\title{
Cross-sectional association between road traffic noise and hypertension in a population-based sample in Girona, Spain (REGICOR-AIR project)
}

\author{
M. Foraster ${ }^{1,2,3,4,5}$, X. Basagaña ${ }^{1,3,5}$, I. Aguilera ${ }^{1,3,5}$, M. Rivera ${ }^{1,3,5}$, D. Agis ${ }^{1,3,5}$, \\ L. Bouso ${ }^{1,3,5}$, A. Deltell ${ }^{6,7}$, J. Dratva ${ }^{8,9}$, D. Juvinyà ${ }^{7}$, J. Sunyer ${ }^{1,3,4,5}$, R. Elosua' ${ }^{2,3}$, \\ N. Künzli ${ }^{8,9}$ \\ 1 Centre for Research in Environmental Epidemiology (CREAL), Barcelona, Spain \\ 2 Instituto de Salud Carlos III (ISCIII), Spain \\ 3 Hospital del Mar Research Institute (IMIM), Barcelona, Spain \\ 4 Universitat Pompeu Fabra (UPF), Barcelona, Spain \\ 5 CIBER Epidemiologia y Salud Pública (CIBERESP), Spain \\ 6 GREFEMA (Grup de Recerca en Enginyeria de Fluids, Energia i Medi Ambient), Girona, Spain \\ 7 University of Girona (UdG), Girona, Spain \\ 8 Swiss Tropical and Public Health Institute Basel (SwissTPH), Basel, Switzerland \\ 9 University of Basel, Switzerland
}

\section{INTRODUCTION}

Long-term exposure to traffic-related noise may increase blood pressure levels and induce hypertension, especially at night-time (WHO 2009). The evidence for the effects of road traffic noise on hypertension seems to be increasing, but some inconsistencies are still found in the size of the effects and in the effect modifiers involved in this association (such as age or gender) (e.g. de Kluizenaar et al. 2007; Bluhm et al. 2007; Belojevic et al. 2008; Jarup et al. 2008; Barregard et al. 2009).

Besides, long-term exposure to traffic-related air pollution has been also associated with cardiovascular health (HEI 2010). There could be some interrelated biological pathways of long-term exposure to road traffic noise and air pollution leading to common cardiovascular endpoints. Therefore, traffic-related air pollution may confound the cardiovascular effects of road traffic noise in the long-term (Foraster et al. 2011). However, to our knowledge, few studies analyzing hypertension could consider air pollution (de Kluizenaar et al. 2007; Jarup et al. 2008).

We evaluated the cross-sectional association between outdoor residential modeled estimates of road traffic equivalent noise levels ( $L_{\text {night }}$ and $\left.L_{24 h}\right)$ and hypertension, adjusting for outdoor long-term modeled estimates of traffic-related air pollution in the city of Girona, north-eastern Spain, within the REGICOR-AIR project. We also evaluated the association by age groups and gender.

\section{METHODS}

We evaluated 3,480 baseline participants (35-83 years old) corresponding to the population-based HERMES cohort (years 2003-2005). Trained nurses administered questionnaires on socio-demographic and lifestyle characteristics and collected information on general and cardiovascular health. They also took blood pressure measurements following the standard procedures of the project, based on the Joint National Committee VII. 
The participants' addresses were automatically geocoded at 2 meters from the façade of the building and their precision was evaluated and corrected manually if necessary. The outdoor residential road traffic equivalent noise levels for the night, 9pm-7am, ( $\left.L_{\text {night }}\right)$ and 24 hours $\left(L_{24 h}\right)$, and outdoor residential long-term averages of nitrogen dioxide $\left(\mathrm{NO}_{2}\right)$ concentrations were derived with a validated city-specific noise model (Environmental Noise Directive 2002/49/EC) and a land-use regression model, respectively.

Hypertension was defined as having a systolic blood pressure $\geq 140 \mathrm{mmHg}$ or a diastolic blood pressure $\geq 90 \mathrm{mmHg}$ or having hypertensive treatment. We performed multivariate logistic regression for the association between hypertension and road traffic noise. The relevant confounders were selected based on literature. The list included age, gender, socio-economic variables, diet, smoking, alcohol consumption, diabetes, body mass index, physical activity, family history of cardiovascular disease, heart rate, hyperlipidemia and air pollution exposure. The analyses were finally adjusted for those covariates that were associated with the outcome and the exposure in the bivariate analyses (with a $p$-value $<0.2$ ) and that contributed to the association in the multivariate analyses (with $p$-value $<0.05$ and a change in the effect estimate for road traffic noise of more than $10 \%)$.

\section{RESULTS}

Our population had an average age of 58 years (range 35-83). The prevalence of hypertension in our population was $42 \%$. The percentage of the population exposed to the different noise categories ( $L_{\text {night }}$ ) was $13.8 \%$ (for less than $50 \mathrm{dBA}$ ), $23.9 \%$ (between 50-54 dBA), 38.6\% (between 55-59 dBA) and 23.7\% (60 dBA or more). The mean $\mathrm{NO}_{2}$ level was $26.7 \mu \mathrm{g} / \mathrm{m}^{3}\left(\mathrm{IQR}=10.75 \mu \mathrm{g} / \mathrm{m}^{3}\right)$.

A non-significant association was found between night-time traffic-related noise and hypertension for an increase of $10 \mathrm{~dB}(\mathrm{~A})$ in $\mathrm{L}_{\text {night }}(\mathrm{OR}=1.02$; $95 \% \mathrm{Cl}$ 0.86-1.20). Results for the relationship between hypertension and $24 \mathrm{~h}$ traffic-related noise were similar for an increase of $10 \mathrm{~dB}(\mathrm{~A})$ in $\mathrm{L}_{24 \mathrm{~h}}(\mathrm{OR}=1.04$; $95 \% \mathrm{Cl} 0.88-1.22)$. This association remained unchanged after adjusting for $\mathrm{NO}_{2}$. No significant associations were observed when using $L_{\text {night }}$ or $L_{24 h}$ in categories of $5 \mathrm{~dB}$ and there was no clear trend in the OR with increasing noise. Results did not change in the stratified analyses by gender or age groups.

\section{CONCLUSIONS}

The overall non-significant positive effect estimates are in line with some previous epidemiological studies. However, we could not confirm some of the reported significant effects observed in previous studies by gender or age groups. Further analyses will include the evaluation of coping behavior against noise and sensitivity analyses on the noise exposure assessment. Furthermore, we will also study the association between blood pressure and road traffic noise.

\section{REFERENCES}

Barregard L, Bonde E, Ohrstrom E (2009). Risk of hypertension from exposure to road traffic noise in a population-based sample. Occup Environ Med 66: 410-415.

Belojevic GA, Jakovljevic BD, Stojanov VJ et al. (2008). Night-time road traffic noise and arterial hypertension in an urban population. Hypertens Res 31: 775-781.

Bluhm GL, Berglind N, Nordling E et al. (2007). Road traffic noise and hypertension. Occup Environ Med 64:122-126. 
Bodin T, Albin M, Ardo J et al. (2009). Road traffic noise and hypertension: results from a cross-sectional public health survey in southern Sweden. Environ Health 8: 38.

Chang TY, Liu CS, Bao BY (2011). Characterization of road traffic noise exposure and prevalence of hypertension in central Taiwan. Sci Total Environ 409: 1053-1057.

de Kluizenaar Y, Gansevoort RT, Miedema HM et al. (2007). Hypertension and road traffic noise exposure. J. Occup Environ Med 49: 484-492.

Foraster M, Deltell A, Basagaña X et al. (2011). Local determinants of road traffic noise levels versus determinants of air pollution levels in a Mediterranean city. Environ Res 111: 177-183.

HEI Panel on Health Effects of Traffic-Related Air Pollution (2010). Traffic-related air pollution: a critical review of the literature on emissions, exposure, and health effects. Health Effects Institute, Boston, A.

Jarup L, Babisch W, Houthuijs D et al. (2008). Hypertension and exposure to noise near airports: the HYENA study. Environ Health Perspect 116: 329-333.

WHO (2009). Night noise guidelines for Europe. Copenhagen: WHO, Regional Office for Europe. 